Sammlung Metzler

Band 254 
Sibylle Späth

\section{Rolf Dieter \\ Brinkmann}

J.B. Metzlersche Verlagsbuchhandlung Stuttgart 
CIP-Titelaufnahme der Deutschen Bibliothek

Späth, Sibylle:

Rolf Dieter Brinkmann / Sibylle Späth.

- Stuttgart : Metzler, 1989

(Sammlung Metzler ; Bd. 254)

ISBN 978-3-476-10254-6

NE: GT

SM 254

ISBN 978-3-476-10254-6

ISBN 978-3-476-03956-9 (eBook)

DOI 10.1007/978-3-476-03956-9

Dieses Werk einschließlich aller seiner Teile ist urheberrechtlich geschützt. Jede Verwertung außerhalb der engen Grenzen des Urheberrechtsgesetzes ist ohne Zustimmung des Verlages unzulässig und strafbar. Das gilt insbesondere für Vervielfältigungen, Übersetzungen, Mikroverfilmungen und die Einspeicherung und Verarbeitung in elektronischen Systemen.

(C) 1989 Springer-Verlag GmbH Deutschland

Ursprünglich erschienen bei J.B. Metzlersche Verlagsbuchhandlung und Carl Ernst Poeschel Verlag GmbH in Stuttgart 1989 


\section{Inhaltsverzeichnis}

Einleitung $\ldots \ldots \ldots \ldots \ldots \ldots \ldots \ldots \ldots \ldots \ldots \ldots \ldots \ldots \ldots \ldots$

Schwieriges Erbe:

Lyrik zwischen Tradition und Innovation. Gedichte 1962-1967

Ihr nennt es Sprache ...................... 4 Le Chant du Monde. Ohne Neger. \&-Gedichte. Was fraglich

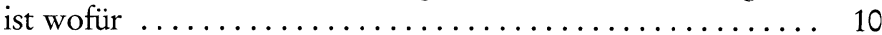

Prosa der Formexperimente

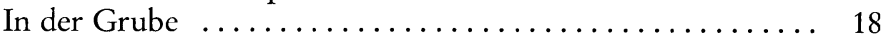

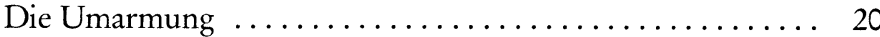

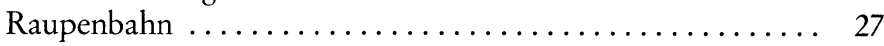

Die Bootsfahrt .......................... 32

Was unter die Dornen fiel .................... 33

Kurzprosa $1965-1967 \ldots \ldots \ldots \ldots \ldots \ldots \ldots \ldots \ldots \ldots \ldots$

Talking about my generation I

Keiner weiß mehr ......................... 38

Imaginationsräume. Die Leinwand, der schwarze

Kasten und das weiße Papier. Gedichte 1968-1970

Poetologie ................................ 42

Godzilla .............................. 47

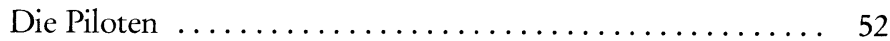

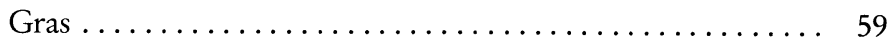

Science-Fiction

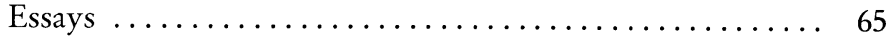

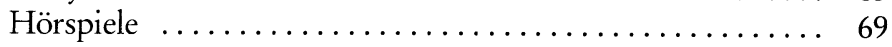

Traummaschine Körper

Eiswasser an der Guadelupe Str. . . . . . . . . . . . . 73

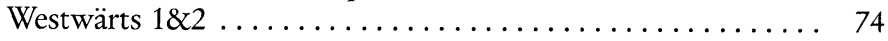


Talking about my generation II.

Reisebericht, Briefroman, Tagebuch $\ldots \ldots \ldots \ldots \ldots \ldots \ldots .91$

Erkundungen für die Präzisierung des Gefühls für

einen Aufstand: Reise Zeit Magazin (Tagebuch) $\ldots \ldots \ldots \ldots \quad 97$

Rom, Blicke

Reisebericht ................................ 102

Postkarte und Photographie ........................ 107

Briefroman ................................. 108

Intertextualität $\ldots \ldots \ldots \ldots \ldots \ldots \ldots \ldots \ldots \ldots \ldots, 111$

Schnitte

Nachrichten-Magazin $\ldots \ldots \ldots \ldots \ldots \ldots \ldots \ldots \ldots \ldots, 114$

Anhang

Kurzbiographie $\ldots \ldots \ldots \ldots \ldots \ldots \ldots \ldots \ldots \ldots \ldots \ldots, 117$

Werkverzeichnis .............................. 118

Literatur über Brinkmann ..................... 122

In Abkürzungen zitierte Literatur . . . . . . . . . . . . . 134 